\title{
Scavengers Protection of Cells Against ALA-based Photodynamic Therapy-induced Damage
}

\author{
C. Perotti, H. Fukuda, A. Casas and A.M. del C. Batlle \\ Centro de Investigaciones sobre Porfirinas y Porfirias (CIPYP) FCEyN (University of Buenos Aires and CONICET), \\ Ciudad Universitaria, Pabellón II, 2do piso, (1428), Buenos Aires, Argentina
}

\begin{abstract}
The exogenously stimulated formation of intracellularly generated protoporphyrin IX, a precursor of haem, is becoming one of the fastest developing areas in the field of photodynamic therapy (PDT). We tested the action of several free radical scavengers, amino acids, antioxidants and sulphur-containing compounds as protectors from photodamage induced by 5-aminolaevulinic acid (ALA)-mediated PDT, employing the LM2 cell line, derived from a mammary murine adenocarcinoma. We exposed the cells to different concentrations of the compounds, $24 \mathrm{~h}$ before PDT, during PDT, and $19 \mathrm{~h}$ after treatment. We defined the protection grade $(\mathrm{PG})$ as the ratio between cell survival after ALA-PDT treatment in the presence of the protector and cell survival of ALA-PDT treatment alone. We found that L-tryptophan $(\mathrm{PG}=9.2$ at $2 \mathrm{~mm})$, reduced glutathione $(\mathrm{GSH})(\mathrm{PG}=5.8$ at $0.8 \mathrm{~mm}), N$-acetyl-L-cysteine $(\mathrm{PG}=4.86$ at $30 \mathrm{~mm})$, melatonin $(\mathrm{PG}=4.5$ at $8 \mathrm{~mm})$ and L-methionine $(\mathrm{PG}=4.0$ at $0.8 \mathrm{~mm})$ are the best protectors from PDT damage, followed by L-cysteine $(\mathrm{PG}=2.8$ at $0.8 \mathrm{~mm})$, mannitol $(\mathrm{PG}=2.6$ at $20 \mathrm{~mm})$ and glycine $(\mathrm{PG}=2.4$ at $40 \mathrm{~mm})$ whereas oxidised glutathione and $S$-adenosyl-L-methionine do not exert any protection. We did not found any photoactive action of the protectors in absence of ALA. These results can be considered to modulate the photodamage induced by ALA-PDT.
\end{abstract}

Keywords: Aminolaevulinic acid; Photodynamic therapy; PDT; Scavengers.

\section{INTRODUCTION}

Photodynamic therapy (PDT) is a cancer treatment modality that, through the administration of an exogenous tumour-localising photosensitiser, mainly porphyrins, followed by an adequate dose of photoactivating light destroys malignant tissues [1]. New perspectives have been opened by the use of the porphyrin precursor 5-aminolaevulinic acid (ALA), from which synthesis of the photosensitiser protoporphyrin IX (PpIX), is accomplished in situ $[2,3]$.

The initial photodynamic effect is the lightcatalysed formation of active oxygen species, notably singlet molecular oxygen $\left({ }^{1} \mathrm{O}_{2}\right)[4]$ by a type II reaction and the generation of free radicals and other reactive intermediates such as hydroxyl radical $(\mathrm{OH})$ and the superoxide

Correspondence to: Professor A. Batlle, Viamonte 1881 10A, 1056 Buenos Aires, Argentina. Fax: 54114811 7447; e-mail: batlle@mail.retina.ar anion by a type I reaction [5]. The oxidation of cellular constituents by these reactive oxygen species (ROS) damages plasma membranes and subcellular organelles.

Cellular protection mechanisms by way of superoxide dismutase and the scavenger glutathione avoided damage to organelles driven by the phototoxic action of PpIX [6]. When the scavengers trolox or $\alpha$-tocopherol succinate were present during irradiation, the appearance of apoptotic cells and cytotoxic effects in murine leukaemia cells treated with photosensitisers with lysosomal targets was prevented [7]. Early apoptotic signals generated by PDT were inhibited by the singlet oxygen scavengers L-histidine and $\alpha$-tocopherol, but not by hydroxyl radical scavengers [8].

Porphyrin accumulation from ALA in epidermal cells was decreased in the presence of sodium azide or mannitol [9]. Mannitol is a well-known hydroxyl radical scavenger, whereas tryptophan, reduced glutathione (GSH) and sodium azide, among others, are antioxidants protecting organisms against singlet oxygen. 
Glutathione has been shown to play a critical role in cellular defence against a variety of injurious agents. Under normal steady-state conditions, most of the glutathione exists in its reduced form. Oxidation of GSH, either nonenzymatically or by the action of glutathione peroxidase, yields glutathione disulphide (GSSG). NADPH-dependent reduction of GSSG by glutathione reductase, as well as its efflux, effectively mantains the intracellular concentration of GSH. Thus, in many cell types, the glutathione oxidation-reduction cycle helps to mantain structural and functional viability in spite of endogenous production of ROS overproduced during acute oxidant injury.

Intracellular thiols may play a role in the mechanisms of cancer treatment modalities such as ionising radiation, chemotherapy and hyperthermia [10]. A number of reports have shown that resistance to chemotherapeutic agents may be due to elevated cellular GSH concentrations $[11,12]$. These studies have indicated that GSH may be involved in protecting cells via detoxification of cytotoxic species, such as scavenging of free radicals and in the repair of oxidative cellular damage by hydrogen donation. It has also been suggested that GSH may influence DNA repair [13] as well as help to mantain membrane integrity via the formation of mixed disulphides [14]. GSH can act against singlet oxygen and superoxide anion radical [15]. Moreover, GSH depletion sensitises cells to photodynamic damage [16].

$S$-adenosyl-L-methionine (SAM) is a precursor of GSH which, unlike GSH itself, can readily cross cell membranes. It has been shown that supplementation of organ preservation solutions with SAM instead of GSH has improved hydroxyl radical and singlet oxygen scavenging, as well as chelation of iron ions [15].

Another sulphur-containing compound, $N$ acetyl-L-cysteine (NAC), also increases GSH levels by providing cysteine and it is known to prevent pathologies elicited by free radicals and ROS [17]. Tao et al. [18] found that NAC significantly overcame the effect on PDT-induced stress-activated protein kinase. It was also found that NAC protected against apoptosis mediated by pyropheophorbide-amethylester in colon cancer cells [19]. However, NAC failed to attenuate PpIX-induced photosensitivy in erythropoietic protoporphyria [20] and patients treated with Photofrin [21].
In addition, the non-sulphur amino acid glycine, was shown to protect human endothelial cells from $\mathrm{H}_{2} \mathrm{O}_{2}$-induced lethal injury and also to diminish radiation-induced cytotoxicity in bovine endothelial cells [22,23].

The aim of this work was to evaluate the protector action of some free radical scavengers, amino acids, antioxidants and sulphurcontaining compounds against the cytotoxic photodynamic action of ALA-PDT.

\section{MATERIALS AND METHODS}

\section{Chemicals}

ALA, L-cysteine, L-trypthophan, L-methionine, glycine, mannitol, melatonin, $S$-adenosylmethionine (SAM), $N$-acetyl-Lcysteine (NAC), reduced glutathione (GSH) and oxidised glutathione (GSSG) were obtained from Sigma Chem Co.

\section{Cell Line and Cell Culture}

Cell line LM2 [24] derived from murine mammary adenocarcinoma M2 (Instituto Roffo, Buenos Aires) was cultured in minimum essential Eagle's medium (MEM), supplemented with $2 \mathrm{~mm}$ L-glutamine, $40 \mu \mathrm{g}$ gentamycin $/ \mathrm{ml}$ and $5 \%$ fetal bovine serum (FBS), and incubated at $37^{\circ} \mathrm{C}$ in an atmosphere containing $5 \% \mathrm{CO}_{2}$.

\section{ALA-PDT Treatment}

Cells $\left(3.5 \times 10^{4}\right.$ per well) were incubated in serum-free medium containing $0.2 \mathrm{~mm}$ ALA in 24-well plates, and $3 \mathrm{~h}$ later, laser irradiations were performed. After $5 \mathrm{~min}$ of irradiation, medium was replaced by ALA-free medium + fetal bovine serum, cells were incubated for another $19 \mathrm{~h}$ and then tested for viability. Irradiations were performed using a rhodamine dye laser (Model DL30, Oxford Lasers) pumped by a copper vapour laser (CU15A, Oxford Lasers) tuned to $630 \mathrm{~nm}$. The light was focused into a $400 \mu \mathrm{m}$-diameter optical fibre coupled to a frontal light distributor (Model FD2, Medlight, Ecublens, Switzerland) to produce a treatment area of uniform intensity. The output power from the fibre was measured with a power meter (Model LM-100XL, Coherent, Auburn, CA) before each 
application, and adjusted to the desired light dose $\left(4.6 \mathrm{~J} / \mathrm{cm}^{2}\right)$. Non-ALA and non-irradiated controls were also run.

\section{Drug Exposure}

The scavengers, amino acids, antioxidants and sulphur-containing compounds were dissolved in sterile Earle's salts, $\mathrm{pH} 7.4$ and added to the cells $24 \mathrm{~h}$ before PDT. They were also present during the 3-h exposure to ALA, during the $5 \mathrm{~min}$ of laser irradiation and $19 \mathrm{~h}$ after treatment.

\section{MTT Viability Assay}

Phototoxicity/toxicity was documented by the MTT assay [25], a method based on the activity of mitochondrial dehydrogenases, which will be functionally affected by PDT in vitro [26]. At $19 \mathrm{~h}$ after treatments, MTT (3-[4,5dimethylthiazol-2-yl]-2,5-diphenyltetrazolium bromide) solution was added to each well at a concentration of $0.5 \mathrm{mg} / \mathrm{ml}$, and plates were incubated at $37^{\circ} \mathrm{C}$ for $1 \mathrm{~h}$. The resulting formazan crystals were dissolved by the addition of dimethylsulphoxide (DMSO) and absorbance was read at $560 \mathrm{~nm}$.

\section{Cell Number}

The number of cells seeded per well was determined by counting viable cells with the Trypan blue exclusion method.

\section{RESULTS}

\section{Effect of Protectors on Cell Survival induced by ALA-PDT, ALA and Light Exposure}

Figures 1-4 show the action of some free radical scavengers, amino acids, antioxidants and sulphur-containing compounds on cell viability under four different experimental conditions: the impact of the protector itself on cell viability, the potential photoactive action of the compound when illuminated, the cytotoxic action of the compound when coincubated with ALA and the effect of the compound in modifying ALA-PDT induced cytotoxicity. ALA concentration and time exposure as well as light conditions were determined in previous work [27].
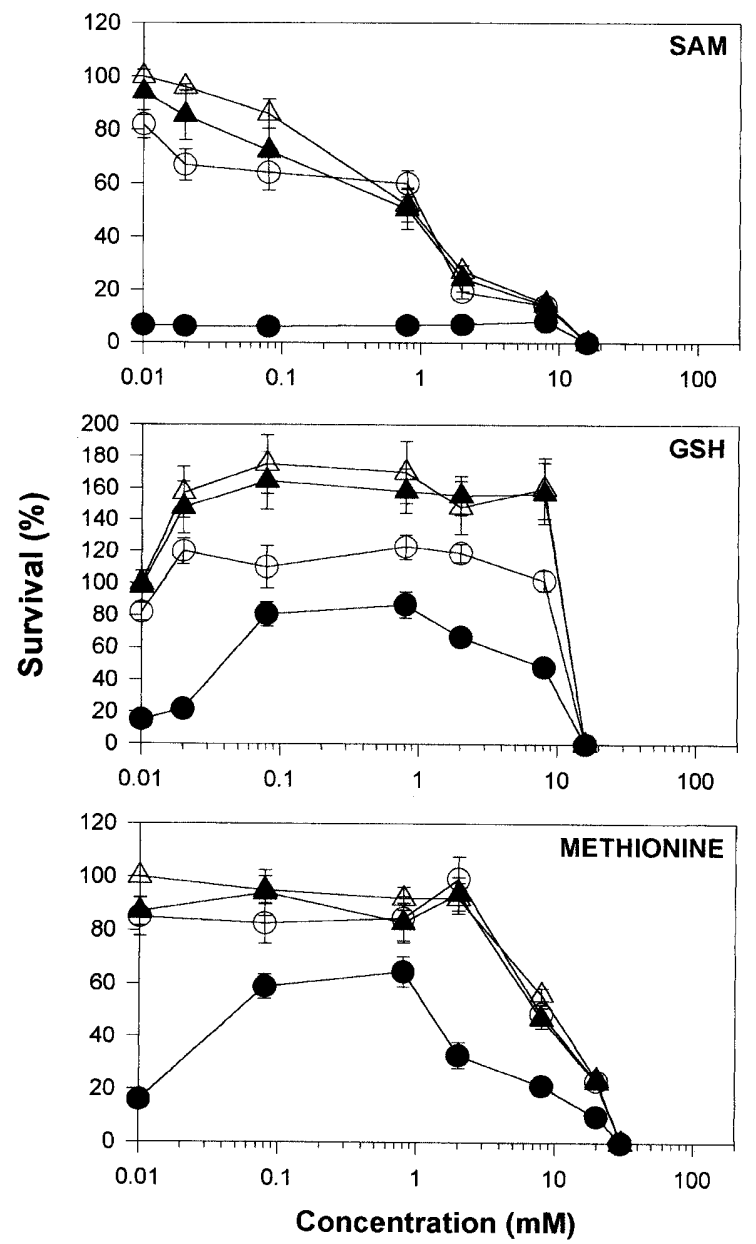

Fig. 1. Effects of SAM, GSH and methionine on cell survival induced by PDT, ALA and light exposure. Tryptophan and mannitol were added to the cells from $24 \mathrm{~h}$ before PDT to $19 \mathrm{~h}$ after treatment, ALA and light exposure period included. PDT-treated cells $(\bullet)$, ALA-treated cells $(\bigcirc)$, light-irradiated cells $(\boldsymbol{\Delta})$ and untreated control cells $(\triangle)$. MTT assay was performed after replacing the medium with free-scavenger medium. The percentage of survival was referred to control cells neither PDT-treated nor exposed to scavengers. Each data point represents the average of three determinations. Error bars show standard deviations.

None of the compounds were cytotoxic by themselves at low concentrations, however, they decreased cell viability by more than $20 \%$ at higher and different concentrations for each compound: SAM $0.02 \mathrm{~mm}$, melatonin and cysteine $3 \mathrm{~mm}$, glycine and methionine $4 \mathrm{~mm}$, GSSG $15 \mathrm{~mm}$ and NAC, tryptophan, GSH and mannitol $20 \mathrm{mM}$.

We did not find any photoactive action of the protectors by themselves. When the compounds were coincubated with ALA in the absence of light, in most cases there was a general reversion of the dark toxicity induced by ALA. The exception was GSSG, that enhanced ALA-induced cytotoxicity. As a 


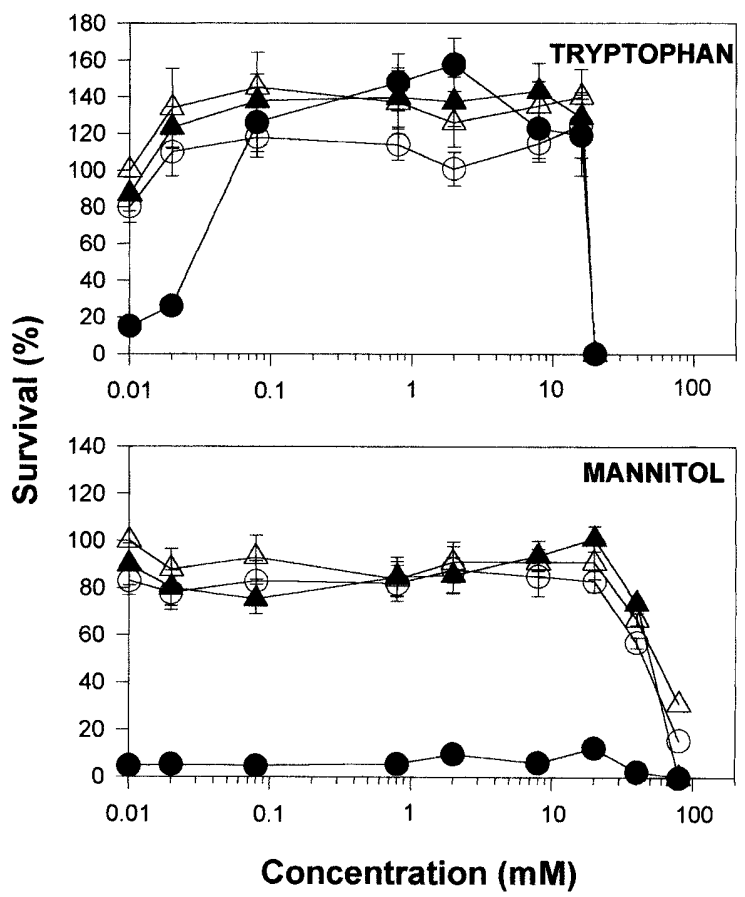

Fig. 2. Effects of tryptophan and mannitol on cell survival induced by PDT, ALA and light exposure. SAM, GSH and methionine were added to the cells from $24 \mathrm{~h}$ before PDT to $19 \mathrm{~h}$ after treatment, ALA and light exposure period included. PDT-treated cells $(\bullet)$, ALA-treated cells $(\bigcirc)$, light-irradiated cells $(\boldsymbol{\Delta})$ and untreated control cells $(\triangle)$. MTT assay was performed after replacing the medium with free-scavenger medium. The percentage of survival was referred to control cells neither PDT-treated nor exposed to scavengers. Each data point represents the average of three determinations. Error bars show standard deviations.

general pattern, the concentrations affording protection against ALA-induced cytotoxicity were coincident with the concentrations protecting against PDT. The effect of these protectors on the cytoxicity induced by ALA-PDT compared to the behaviour of PDT-treated cells in their absence, is further examined in Figs 5 and 6.

\section{Influence of Protectors on Cell Survival after ALA-PDT}

To study the effect of the free radicals scavengers, amino acids, antioxidants and sulphur-containing compounds comparatively, we defined the protection grade (PG) as the ratio between cell survival after ALA-PDT treatment in the presence of the different compounds and cell survival without protectors.

Maximum protection grades were found at varying concentrations depending on the compound. L-Tryptophan $(\mathrm{PG}=9.2$ at $2 \mathrm{mM}), \mathrm{GSH}$ $(\mathrm{PG}=5.8$ at $0.8 \mathrm{~mm}), \mathrm{NAC}(\mathrm{PG}=5.3$ at $20 \mathrm{~mm})$,

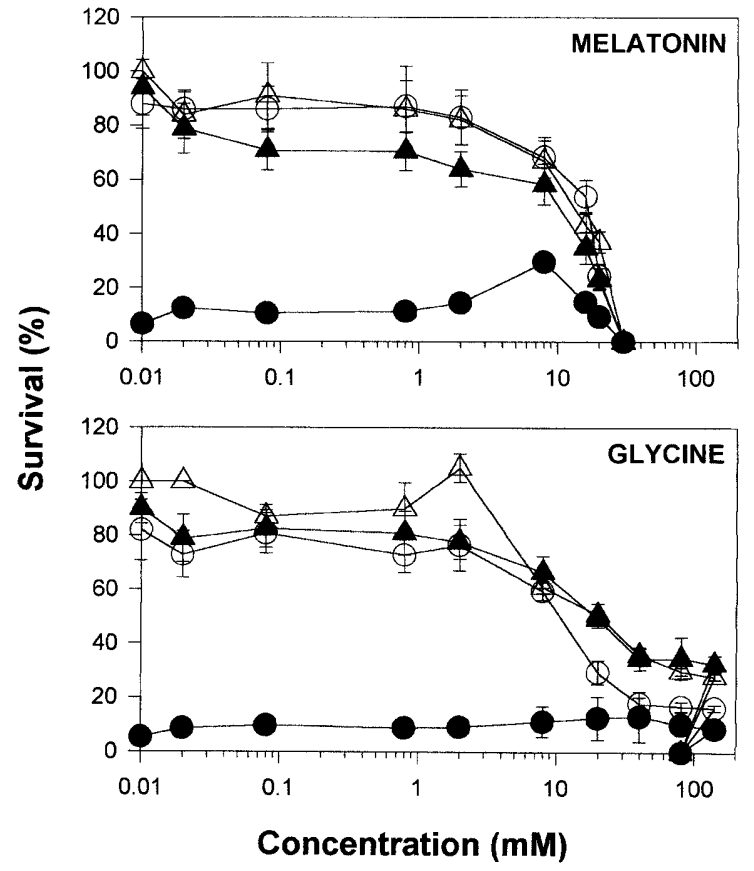

Fig. 3. Effects of melatonin and glycine on cell survival induced by PDT, ALA and light exposure. NAC, cysteine and GSSG were added to the cells $24 \mathrm{~h}$ before PDT, during ALA and light exposure period and $19 \mathrm{~h}$ after treatment. PDTtreated cells $(\bullet)$, ALA-treated cells $(\bigcirc)$, light-irradiated cells $(\mathbf{\Delta})$ and untreated control cells $(\triangle)$. MTT assay was performed after replacing the medium with free-scavenger medium. The percentage of survival was referred to control cells neither PDT-treated nor exposed to scavengers. Each data point represents the average of three determinations. Error bars show standard deviations.

melatonin $(\mathrm{PG}=4.5$ at $8 \mathrm{~mm})$ and L-methionine $(\mathrm{PG}=4.0$ at $0.8 \mathrm{~mm})$ were found to be the best protectors from PDT damage at their optimal concentrations, followed by L-cysteine $(\mathrm{PG}=2.8$ at $0.8 \mathrm{mM})$, mannitol $(\mathrm{PG}=2.6$ at $20 \mathrm{~mm})$ and glycine $(\mathrm{PG}=2.4$ at $40 \mathrm{~mm})$. Oxidised glutathione and $S$-adenosyl-L-methionine did not exert any protection.

In a parallel set of experiments, cells were exposed to protectors, prior to PDT, during PDT, and after PDT separately, and in a combination of these experimental conditions. We found that the maxima PGs were reached when cells were treated with the protector before and during PDT; its addition after PDT did not improve cell survival (data not depicted).

\section{DISCUSSION}

L-Tryptophan, a well-known and efficient singlet oxygen quencher (Table 1), was the best protector among all the compounds assayed, affording a $\mathrm{PG}$ of 9.2 at a concentration as low 

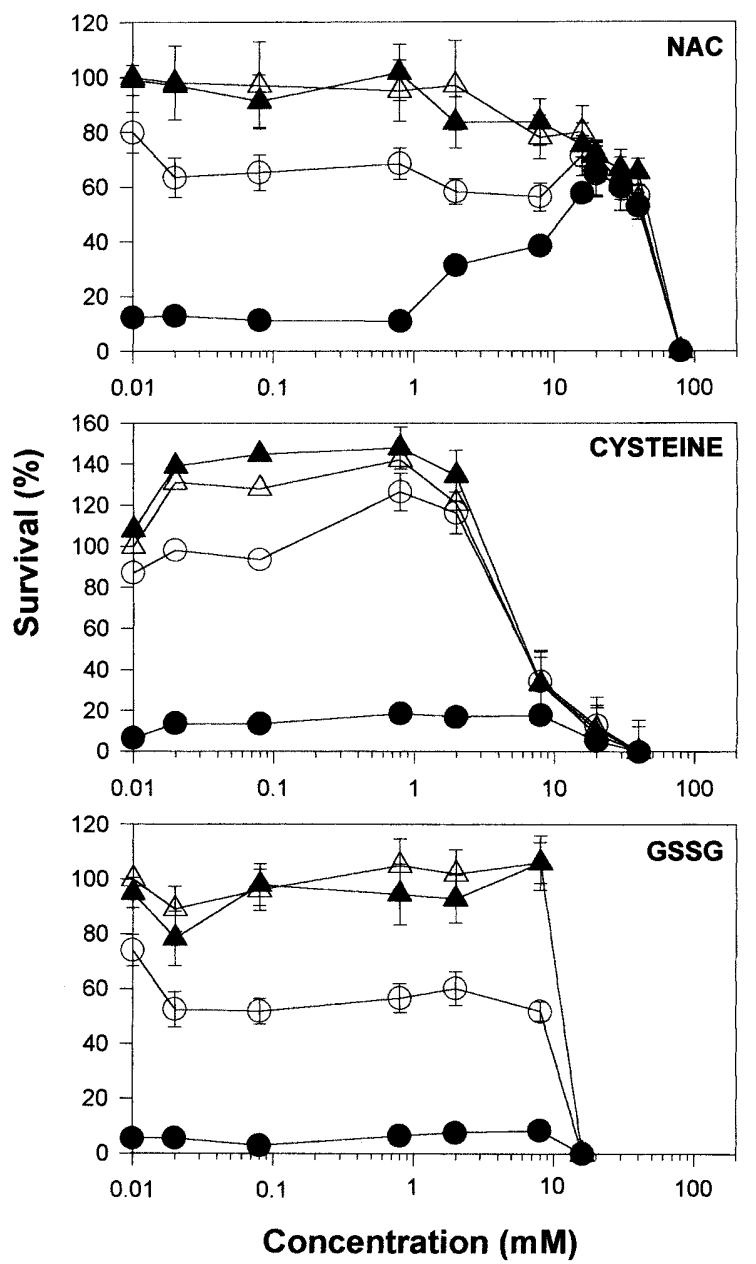

Fig. 4. Effects of NAC, cysteine and GSSG on cell survival induced by PDT, ALA and light exposure. Melatonin and glycine were added to the cells $24 \mathrm{~h}$ before PDT, during ALA and light exposure period and $19 \mathrm{~h}$ after treatment. PDTtreated cells $(\bullet)$, ALA-treated cells $(\bigcirc)$, light-irradiated cells $(\Delta)$ and untreated control cells $(\triangle)$. MTT assay was performed after replacing the medium with free-scavenger medium. The percentage of survival was referred to control cells neither PDT-treated nor exposed to scavengers. Each data point represents the average of three determinations. Error bars show standard deviations.

as $2 \mathrm{~mm}$. On the other hand, the hydroxyl radical scavenger mannitol afforded little protection $(\mathrm{PG}=2.6$ at $20 \mathrm{mM})$. Although lack of specificity of free radical quenching should be considered, these findings may underline the predominant role of ${ }^{1} \mathrm{O}_{2}$ in ALA-PDT cell killing.

Regarding the sulphur-containing compounds, GSH was highly protective. The essential amino acid methionine can be converted into SAM, which through a series of transulphuration reactions yields cysteine and from cysteine comes GSH. The aminothiol NAC can scavenge free radicals through binding of the reduced sulphydryl group, either by

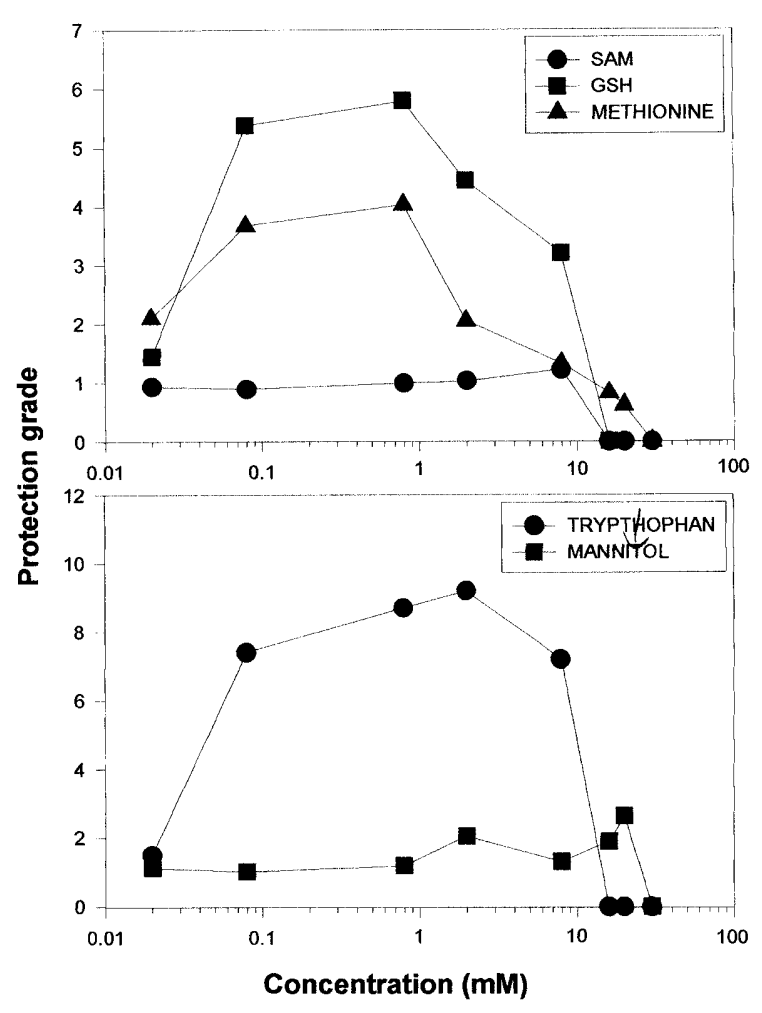

Fig. 5. Influence of protectors on cell survival after ALAPDT. SAM, GSH, methionine, tryptophan and mannitol were added to the cells $24 \mathrm{~h}$ before PDT, during ALA and light exposure period and $19 \mathrm{~h}$ after treatment. MTT assay was performed after replacing the medium with free-scavenger medium. PG is the ratio between cell survival after ALA-PDT treatment in the presence of the different compounds and cell survival without protectors.

thiol metabolism or by enhancing GSH metabolism. NAC itself can act as a singlet oxygen quencher. In vivo, NAC forms cysteine, cystine, methionine, glutathione and mixed sulphides [28].

In this study GSH $(\mathrm{PG}=5.8$ at $0.8 \mathrm{~mm}), \mathrm{NAC}$ $(\mathrm{PG}=5.3$ at $20 \mathrm{~mm})$ and methionine $(\mathrm{PG}=4.0$ at $0.8 \mathrm{~mm}$ ), when used at their maximal protection concentrations, afforded higher protection against ALA-PDT damage than L-cysteine $(\mathrm{PG}=2.8$ at $0.8 \mathrm{~mm})$, which afforded only a slight protection. However it should be noted that much higher NAC concentration is needed to induce the same effect as that produced by GSH. Although for most of the compounds maxima protection grades were reached at relatively high concentrations, it has to be taken into account that concentrations above $1 \mathrm{~mm}$ are not pharmacologically relevant.

Unexpectedly, SAM did not show any protection against ALA-PDT, perhaps because at the concentrations tested, higher than $0.02 \mathrm{~mm}$, it appears to have some toxic effect. As 


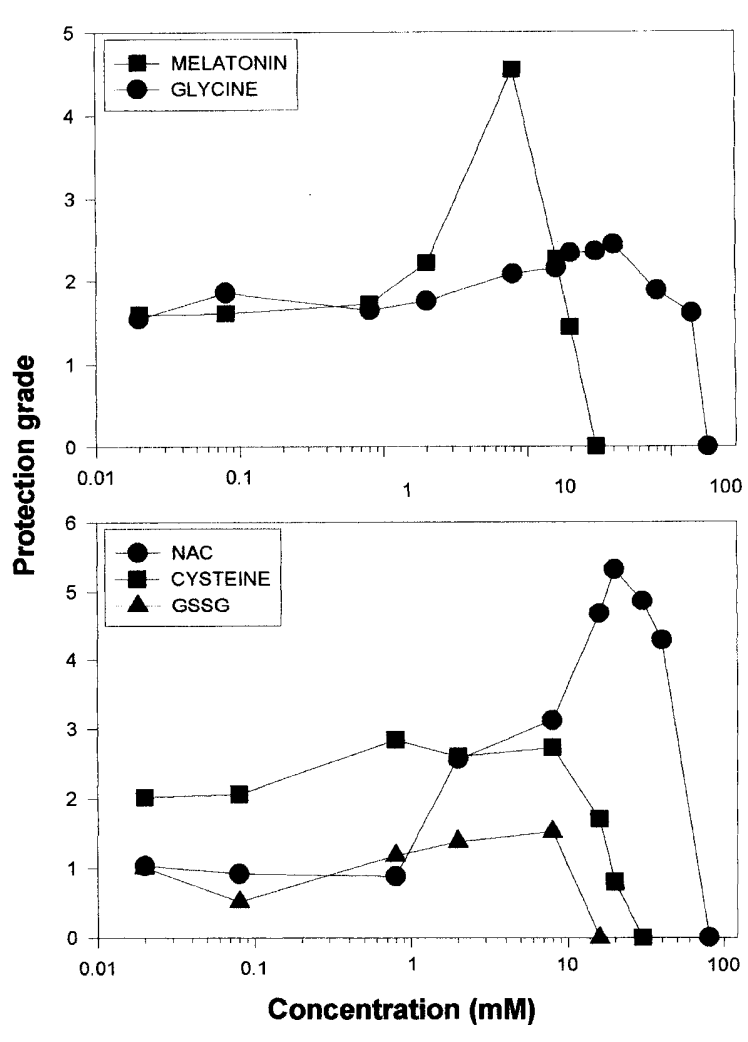

Fig. 6. Influence of protectors on cell survival after ALAPDT. Glycine, melatonin, NAC, cysteine and GSSG were added to the cells $24 \mathrm{~h}$ before PDT, during ALA and light exposure period and $19 \mathrm{~h}$ after treatment. MTT assay was performed after replacing the medium with free-scavenger medium. PG is the ratio between cell survival after ALA-PDT treatment in the presence of the different compounds and cell survival without protectors.

expected, the oxidised form of glutathione, GSSG, neither protected nor enhanced PDT-induced photoxicity.
Cell viability of both non-treated controls and ALA-PDT-treated cells increased $60 \%$ in the presence of GSH, showing an unspecific cell metabolism activation. On the other hand, tryptophan increases $40 \%$ non-treated cells viability but a much higher increase $(140 \%)$ is observed in PDT treated cells, demonstrating in addition, a specific protection against photodamage.

The pineal hormone melatonin is a potent hydroxyl radical scavenger [29]. Additionally, melatonin has been reported to neutralise hydrogen peroxide, singlet oxygen, peroxynitrite anion and nitric oxide, and it also stimulates several antioxidative enzymes [30]. In our study we proved that this hormone is an excellent protector $(\mathrm{PG}=4.5$ at $8 \mathrm{~mm})$, at nearly the same level as the the sulphur-containing compounds NAC and methionine.

In addition to singlet oxygen, which is the primary cytotoxic agent in PDT, other interconvertible reactive oxygen species, in particular $\mathrm{OH}$ [31] are also generated. Moreover, ${ }^{1} \mathrm{O}_{2}$, which is a powerful active oxygen form but not a free radical, may induce the formation of oxygen free radicals [32,33]. These two facts explain the ability of the radical scavengers to protect from ALA-PDT-induced damage.

The protection exerted by the non-sulphur amino acid tryptophan is probably due to quenching of ${ }^{1} \mathrm{O}_{2}$ to photooxidation [31] and the slight action of glycine may be ascribed to direct oxidation of the molecule [21]. In agreement with our results, Henderson and Miller [31] found that tryptophan largely abolished PDT cell damage induced by Photofrin in CHO

Table 1. Action of some free radical scavengers, amino acids, antioxidants and sulphur-containing compounds agains ALA-PDT damage

Mode of action
Protection from ALA-PDT damage

No protection

SAM Precursor of GSH. Can Cross cell membranes

NAC Scavenge by thiol metabolism or enhancing GSH metabolism. ${ }^{1} \mathrm{O}_{2}$ quencher

GSH Scavenger of free radicals. Hydrogen donation

Cysteine Precursor of GSH

GSSG Product of GSH oxidation. No protective action

Methionine Precursor of GSH

Tryptophan Mainly ${ }^{1} \mathrm{O}_{2}$ quencher

Mannitol Mainly $\mathrm{OH}$ scavenger

Glycine Oxidation helps to maintain cellular redox state

Melatonin Mainly $\mathrm{OH}$ but also scavenger of many free radicals

\section{Protective}

Protective

Slight protection No protection

Protective

Best protection

Slight protection

Slight protection

Protective 
cells. Glycine was found to protect against ionising radiation [21], but there were no reports on protection against PDT.

Maximum PGs were found when the cells were protected before and during PDT, whereas protection after PDT did not improve cell survival. In contrast to our results, addition of the radical scavengers trolox or $\alpha$-tocopherol during the $60 \mathrm{~min}$ after irradiation of photosensitised murine leukaemia cells with tin etiopurpurin, afforded partial protection from apoptosis and phototoxicity [7]. However, the lysosomal localisation of the photosensitiser may induce long-persisting photoproducts, which may not occur with PpIX formed from ALA, which localises mainly in mitochondria.

In conclusion, our results concerning cell survival following PDT in the presence of various agents affecting cytotoxic molecular species show that L-tryptophan, an efficient singlet oxygen quencher is the best protector from PDT damage, followed by the sulphurcontaining compounds GSH, NAC and methionine, and the hormone melatonin. The presence of the protectors before and during laser illumination is crucial for protection. These findings are useful in the design of a phototherapeutic strategy imparting better protection for normal tissue against the undesirable effects of PDT.

\section{ACKNOWLEDGEMENTS}

This research was supported by grants from the Argentine National Research Council (CONICET) (PIP 4108/96 and 105508/98-99), the Science and Technology Argentine Agency (STAA) (PICT 05-00000-01861) and the Association for International Cancer Research (AICR-UK, 98-6). The authors are very grateful to Mrs Victoria Castillo for her skillful technical assistance. A.M. del C.B. and H.F. hold the posts of Superior and Associate Researchers at the CONICET. A.C. is a postdoctoral fellow of the CONICET. C.P. is a 'Carrillo-Oñativia' fellow from the Ministerio de Salud Pública.

\section{REFERENCES}

1. Dougherty T. Photodynamic therapy (PDT) of malignant tumors. Crit Rev Oncol Hematol 1984;2:83-116.

2. Kennedy J, Pottier R, Pross G. Photodynamic therapy with endogenous protoporphyrin IX: basic principles and present clinical experience. J Photochem Photobiol B 1990;6:143-8.

3. Fukuda H, Casas A, Chueke F, Paredes S, Batlle A. Photodynamic action of endogenously synthesized porphyrins from aminolevulinic acid, using a new model for assaying the effectiveness of tumoral cell killing. Int J Biochem 1993;25:1395-8.

4. Weishaupt K, Gomer C, Dougherty T. Identification of singlet oxygen as cytotoxic agent in photoinactivation of murine tumor. Cancer Res 1976;36:2326-9.

5. Bonnett R, Lambert C, Land E, Scourides P, Sinclair $\mathrm{R}$, Truscott $\mathrm{T}$. The triplet and radical species of hematoporphyrin and some of its derivatives. Photochem Photobiol 1983;38:1-8.

6. Van Graft M, Boot J. Photodynamic effects of protoporphyrin on the cellular level - an in vitro approach. In vitro Cell Dev Biol Anim 1996;32:394-8.

7. Kessel D, Luo Y. Delayed oxidative photodamage induced by photodynamic therapy. Photochem Photobiol 1996;64:601-4.

8. Chan W, Yu J, Yang S. Apoptotic signalling cascade in photosensitized human epidermal carcinoma A431 cells: involvement of singlet oxygen, c-jun N-terminal kinase, caspase-3 and p21-activated kinase 2. Biochem J 2000;351:221-32.

9. He D, Behar S, Nomura N, Sassa S, Taketani S, Lim H. The effect of porphyrin and radiation on ferrochelatase and 5-aminolevulinic acid synthase in epidermal cells. Photodermatol Photoimmunol Photomed 1995;11: 25-9.

10. Arrick B, Nathan C. Glutathione metabolism as a determinant of therapeutic efficacy: a review. Cancer Res 1984;44:4224-32.

11. Richardson M, Siemann D. DNA damage in cycloposphamide-resistant tumor cells: the role of glutathione. Cancer Res 1995;55:1691-5.

12. Siemann D, Beyers K. In vivo therapeutic potential of combination thiol depletion and alkylating chemotherapy. Br J Cancer 1993;68:1071-9.

13. Revesz M, Larsson A. Induction and repair of singlestrand DNA breaks after X-ray irradiation of human fibroblasts deficient in glutathione. Int J Radiat Biol 1981;40:355-63.

14. Isaacs J, Binkley F. Glutathione dependent control of protein disulfide-sulfhydryl content by subcellular fractions of hepatic tissue. Biochim Biophys Acta 1979;497:192-204.

15. Evans P, Whiteman M, Tredger M, Halliwell B. Antioxidant properties of S-adenosyl-L-methionine: a proposed addition to organ storage fluids. Free Rad Biol Med 1997;23:1002-8.

16. Miller A, Henderson B. The influence of cellular glutathione content on cell survival following photodynamic treatment in vitro. Radiat Res 1986;107:83-94.

17. Patterson C, Butler J, Byrne F, Rhodes M. Oxydant lung injury intervention with sulphydryl reagents. Lung 1986;163:23-32.

18. Tao J, Jasbinder S, Pelech S, Wong G, Levy J. Stimulation of stress-activated protein kinase and p38 HOG1 kinase in murine keratinocytes following photodynamic therapy with benzoporphyrin derivative. J Biol Chem 1996;271:27107-15.

19. Matroule J, Carthy C, Granville D, Jolois O, Hunt D, Piette J. Mechanism of colon cancer cell apoptosis mediated by pyropheophorbide-a methylester photosensitization. Oncogene 2001;20:4070-84.

20. Bijlmer-Iest J, Baarte de la Faille H, van Asbeck B, van Hattum J, van Weelden H, Marx J et al. Protoporphyrin photosensitivity cannot be attenuated by oral N-acetylcysteine. Photodermatol Photoimmunol Photomed 1992;9:245-9. 
21. Baas $P$, van Mamsom I, van Tinteven H, Stewart F, van Zandwijk N. Effect pf N-acetylcysteine on Photofrin induced skin photosensitivity in patients. Lasers Surg Med 1995;16:359-67.

22. Weinberg J, Varani J, Johnson K, Roeser N, Dame N, Davis $J$ et al. Protection of human umbilical vein endothelial cells by glycine and structurally similar aminoacids against calcium and hydrogen peroxide induced lethal cell injury. Am J Pathol 1992;140: 457-71.

23. Ts'ao C, Molteni A, Taylor J. Injury-specific cytotoxic response of tumor cells and endothelial cells. Pathol Res Pract 1996;192:1-9.

24. Galli S, Colombo L, Vanzuli S, Daroqui M, Vidal M, Jasnis A et al. Characterization of a fibroblastoid mammary carcinoma cell line (LM2) originated from a mouse adenocarcinoma. Int J Oncol 2000;17:1259-65.

25. Denizot F, Lang R. Rapid colorimetric assay for cell growth and survival. Modifications to the tetrazolium dye procedure giving improved sensitivity and reliability, J Immunol Methods 1986;89:271-7.

26. Hilf R, Smail D, Murant R, Leakey P, Gibson S. Hematoporphyrin derivative induced photosensitivity of mitochondrial succinate dehydrogenase and selected cytosolic enzymes of R3230AC mammary adenocarcinomas of rats. Cancer Res. 1984;44: 1483-8.

27. Casas A, Fukuda H, Di Venosa G, Batlle A. Photosensitisation and mechanism of cytotoxicity induced by the use of ALA derivatives in photodynamic therapy. Br J. Cancer 2001;85:279-84.

28. Baas P, Oppelaar H, van der Valk M, van Zandwijk N, Stewart F. Partial protection of photodynamic-induced skin reactions in mice by $\mathrm{N}$-acetylcysteine: a preclinical study. Photochem Photobiol 1994;59:448-54.

29. Reiter R, Tan D, Poeggeler B, Chen L, MenendezPelaez A. Melatonin, free radicals and cancer initiation. In: Maestroni G, Conti A, Reitter R (eds) Advances in Pineal Research, Vol. 7. John Libbey, 1994;211-28.

30. Reiter R, Tsan D, Osuna C, Gitto E. Actions of melatonin in the reduction of oxidative stress: a review. J Biomed Sci 2000;7:444-58.

31. Henderson B, Miller A. Effects of scavengers of reactive oxygen and radical species on cell survival following photodynamic treatment in vitro: comparison with ionizing radiation. Radiat Res 1986;108: 196-205.

32. Hideg E, Spetea C, Vass I. Singlet oxygen and free radical production during acceptor- and donor-sideinduced photoinhibition. Studies with spin trapping EPR spectroscopy. Biochim Biophys Acta 1994;1186: 143-52.

33. Buettner G.Thiyl free radical production with hematoporphyrin derivative, cysteine and light: a spin-trapping study. FEBS 1984;177:295-9. 